\title{
Erratum to: The power of using video data
}

\author{
Tz-Li Wang • Ya-Hui Bella Lien · Yu-Ming Kuo
}

Published online: 15 September 2012

(C) Springer Science+Business Media B.V. 2012

\section{Erratum to: Qual Quant DOI 10.1007/s11135-012-9717-0}

Unfortunately, the original version of this article contained a mistake. The third author, Yu-Ming Kuo, was not listed among the authors. The correct representation of the authors and their affiliations are listed above and below and should be treated as definitive by the reader.

The online version of the original article can be found under doi:10.1007/s11135-012-9717-0.

T.-L. Wang $(\varangle) \cdot$ Y.-H. B. Lien · Y.-M. Kuo

Department of Business Administration, National Chung Cheng University, 168, University Rd., Minhsiung Township, Chiayi County 62102, Taiwan, ROC e-mail: tlwangou@gmail.com

Y.-H. B. Lien

e-mail: bmayhl@ccu.edu.tw

Y.-M. Kuo

e-mail: tzustu@gmail.com 